\title{
Crystalline Polymers Based on Dative Boron-Nitrogen Bonds and the Quest for Porosity
}

\author{
Alexander J. Stephens, Rosario Scopelliti, Farzaneh Fadaei Tirani, Euro Solari, and Kay Severin* \\ Institute of Chemical Sciences and Engineering, École Polytechnique Fédérale de Lausanne (EPFL), CH-1015 Lau- \\ sanne, Switzerland \\ Supporting Information Placeholder
}

ABSTRACT: Crystalline networks based on dative-boron-nitrogen bonds were obtained by combining polytopic N-donor ligands with polyboronic esters. The utilization of a tetrahedral boronate ester gave rise to a sheet structure, whereas either a linear polymer or a diamond-like network was observed for a tetrahedral $\mathrm{N}$-donor ligand. The intrinsic flexibility of $\mathrm{B} \leftarrow$ Nlinkages favors tight intermolecular packing and interpenetration in the crystalline state. Amorphous $\mathrm{B} \leftarrow \mathrm{N}$ networks, on the other hand, were found to possess porosity with BET surface areas of up to $\sim 300 \mathrm{~m}^{2} \mathrm{~g}^{-1}$. These materials display processability in organic solvents, and hydrolytic damage can be repaired by simple heating-cooling cycles.

The potential of crystalline porous materials is exemplified by recent advances in the development of metal-organic frameworks (MOFs) ${ }^{1-3}$ and covalentorganic frameworks (COFs). ${ }^{4-6}$ Whilst these materials are renowned for their impressive material properties, they also show some limitations. One constraint is related to the fact that strong bonding interactions are used to aggregate building blocks. As a consequence, MOFs and COFs are typically insoluble following their synthesis. In this regard, crystalline networks based on weak supramolecular interactions could offer an interesting alternative. ${ }^{7}$ Labile intermolecular interactions afford a high degree of processability, allowing networks to be dissolved and reformed from solution. In addition, the absence of heavy metals should afford a higher theoretical surface area per unit weight, and a lower toxicity in comparison to MOFs.

Different supramolecular interactions such as hydrogen bonding, ${ }^{8-10}$ halogen bonding, ${ }^{11,12}$ and $\pi-\pi$ interactions ${ }^{13,14}$ have been used to form crystalline networks. However, their instability is an issue. Removal

of solvent molecules from the networks often results in framework collapse, ${ }^{15,16}$ precluding any porosity. ${ }^{17}$ The few supramolecular networks which show extrinsic porosity are mostly based on hydrogen bonding. ${ }^{18-}$ ${ }^{21}$ However, other directional supramolecular interactions have been identified as promising candiates, ${ }^{22-}$ ${ }^{26}$ and may provide new opportunities in terms of materials properties.

The use of dative boron-nitrogen bonds $(\mathrm{B} \leftarrow \mathrm{N}$ bonds) as a tool to construct supramolecular assemblies has become increasingly popular in recent years. ${ }^{27-34}$ These interactions arise from the donation of electrons from an N-donor ligand to a boron acceptor (Scheme 1a). 35

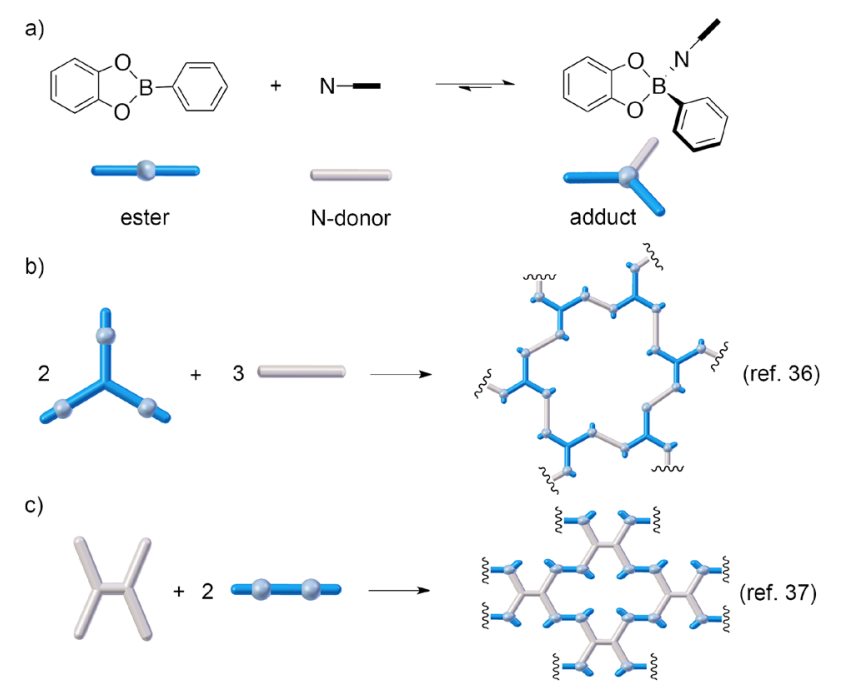

Scheme 1. (a) The coordination of $\mathrm{N}$-donor ligands to boronate esters through dative $\mathrm{B} \leftarrow$ Nbonding (a), and the formation of crystalline $\mathrm{B} \leftarrow$ Nnetworks from polytopic ligands $(\mathrm{b}-\mathrm{c}) \cdot{ }^{36,37}$

The strength of the $\mathrm{B} \leftarrow$ Nbond is strongly influenced by the steric and electronic properties of the interacting components, ${ }^{38-40}$ and has been demonstrated to 
stabilize the otherwise sensitive boronate ester moieties against hydrolysis. ${ }^{41}$ As an alternative to single component self-aggregating networks, ${ }^{42}$ our group has shown that judicious choice of polytopic boronate esters and $\mathrm{N}$-donor ligands can generate well-defined $2 \mathrm{D}$ crystalline networks based on either tritopic ${ }^{36}$ (Scheme 1b) or tetratopic ${ }^{37}$ (Scheme 1c) nodes. However, 3 D networks have remained elusive, ${ }^{43}$ likely due to the exclusive use of planar ligands thus far.

In the pursuit of stable $\mathrm{B} \leftarrow$ Nbonded architectures with ${ }_{3} \mathrm{D}$ connectivity, we decided to focus our efforts on non-planar building blocks constructed around tetrahedral geometries. To this end, selected boronate esters and $\mathrm{N}$-donor ligands were combined in hot 1,2dichlorobenzene or 1,2,4-trichlorobenzene (see SI for full synthetic details). Slow cooling of the various solutions afforded single crystals that were analyzed by $\mathrm{X}$-ray diffraction.

The combination of tetraboronate ester 1 and 4,4'bipyridine resulted in two-dimensional net-shaped polymer 2 (Scheme 2, Figure 1a, $B \leftarrow N v=1.691 \AA$ ). The boronate esters adopt a configuration in which the catechol subunits protrude either above or below the plane of the layer. The rotation of the $\mathrm{C}-\mathrm{B}$ bond is such that the bridging bipyridines align with one another in an alternating fashion throughout the layer, resulting in elongated rhombus-shaped pores with tetraphenylene motifs positioned at the corners. Stacking of layers occurs in an offset pattern, alternating in an ABA fashion. Mutual interpenetration of nets at $90^{\circ}$ is observed (Figure $\mathrm{ib}$ ), significantly reducing void space.

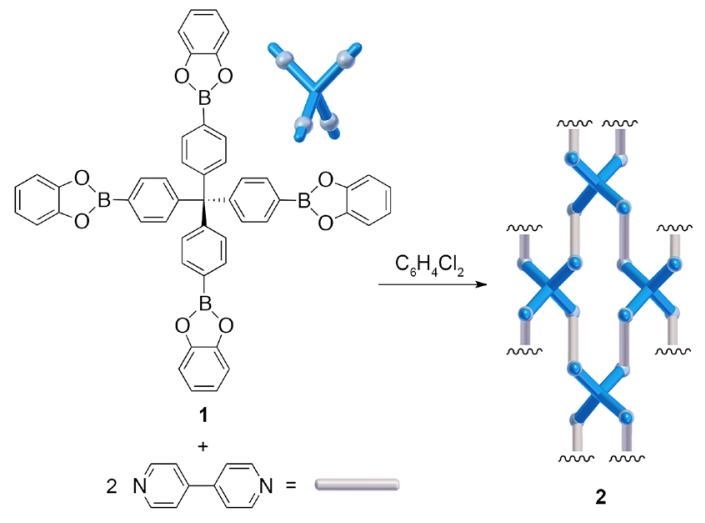

Scheme 2. Synthesis of the $2 \mathrm{D}$ network 2 from tetrahedral boronate ester 1 and 4,4'-bipyridine. a)

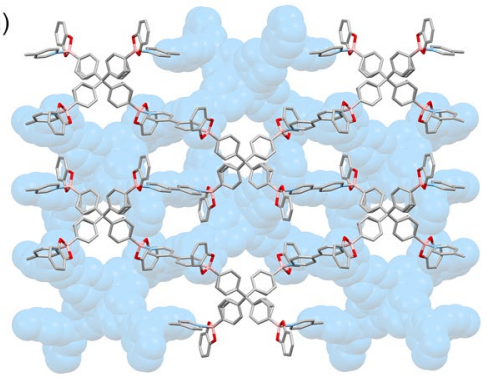

b)

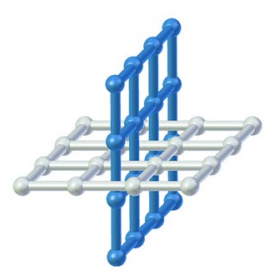

Figure 1. X-ray crystal structures of 2. Superimposed 2D layers in 2 (a), and schematic illustration of interpenetration of 2 at $90^{\circ}$ (b). Discrete layers are indicated by color.

Previous studies have highlighted the use of imidazole $\mathrm{N}$-donors as a means to achieve stronger $\mathrm{B} \leftarrow \mathrm{N}$ bonds. ${ }^{44}$ The use of tetraimidazole $\mathrm{N}$-donor 3 with angular diboronate ester $4 \mathbf{a}$ gave the $1 \mathrm{D}$ polymer $\mathbf{5}$ (Scheme 3, Figure 2a, $\mathrm{B} \leftarrow \mathrm{N}_{\mathrm{d}}=1.632 \AA$ ). Large solventoccupied cavities are created through the offset bridging of tetrahedral nodes both perpendicular and parallel to the direction of chain propagation. Although these cavities align to create persistent channels in the crystal structure packing (Figure S12), no significant porosity was detected by gas sorption experiments.
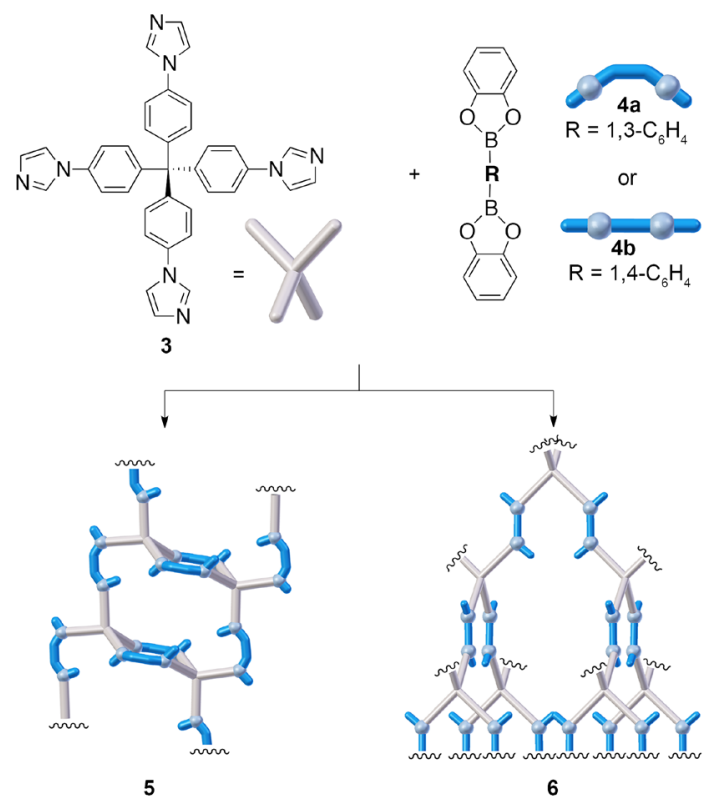

Scheme 3. Synthesis of $2 \mathrm{D}$ polymer 5 and ${ }_{3} \mathrm{D}$ network 6 from tetrahedral $\mathrm{N}$-donor 3 and a ditopic boronate esters $\mathbf{4} \mathbf{a}$ and $\mathbf{4} \mathbf{b}$. 
a)

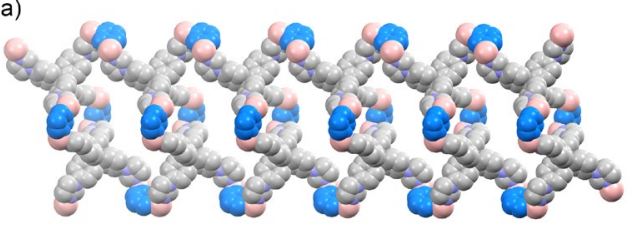

b)

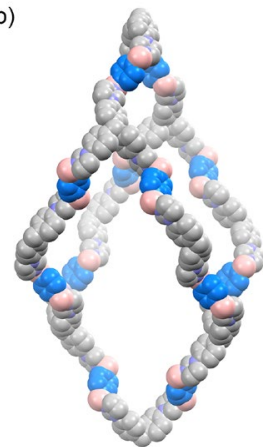

c)

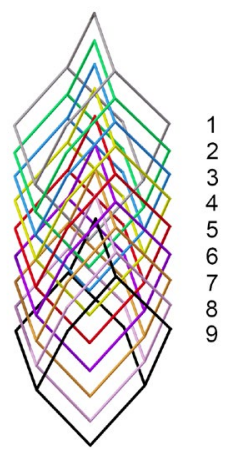

Figure 2. X-ray crystal structures of $1 \mathrm{D}$ polymer 5 (a), and diamondoid 3D network 6 (b). Catechol groups are omitted for clarity, boronate ester carbons are blue. Schematic illustration of the 9-fold interpenetration in $6(\mathrm{c})$.

Using linear diboronate ester $\mathbf{4} \mathbf{b}$ resulted in the formation of the $3 \mathrm{D}$ network $\mathbf{6}$ with a diamond-like

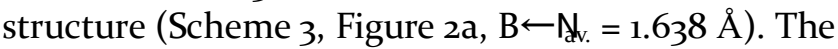
adamantane-shaped substructure of $\mathbf{5}$ shows a large

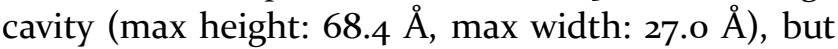
9 -fold interpenetration results in very little void space within the network (Figure 2). Indeed, it appears that no residual solvent molecules are contained in the solid state structure.

It is apparent that the pseudo-tetrahedral $\mathrm{B} \leftarrow \mathrm{N}$ bonding sites play an influential role in determining network topology. A common technique in crystal engineering is to select rigid building blocks to ensure that geometric restraints drive the formation of a desired network topology.4,45,46 However, the intrinsic conformational flexibility of the C-B-N linkage in $\mathrm{B} \leftarrow$ Nhetworks makes it difficult to exert the same level of control over their connectivity. As such, despite the use of non-planar $(3 \mathrm{D})$ ligands $\mathbf{1}$ and 3 with simple ditopic linkers, the components are able to orientate in such a way that $1 \mathrm{D}$ and $2 \mathrm{D}$ structures are still formed. A further consequence of this conformation flexibility is that the networks are able to pack very tightly. Whilst interpenetration can be a useful tool to stabilize crystalline networks for porosity, ${ }^{47}$ the resulting absence of void space or channels observed here precludes the uptake of guests.

To broaden our study, the combination of $\mathbf{1}$ with bent diimidazole ligands of varying lengths and chelating angle was investigated (Scheme 4). The components were combined in hot toluene, and cooled to

room temperature without any regulation. In all cases, powders formed, which were isolated and stored in pentane overnight to exchange any residual toluene.

Analysis of the digested networks ${ }^{48}$ by ${ }^{1} \mathrm{H}$ NMR showed the anticipated 1:2 ratio of $1: \mathrm{N}$-donor in all networks (Figures $\mathrm{S}_{1}-\mathrm{S}_{5}$ ). After evacuation of the networks under reduced pressure, the polymers were characterized by $\mathrm{N}_{2}$ physisorption analysis at $77 \mathrm{~K}$ to calculate their apparent Brunauer-Emmett-Teller (BET) surface areas (Figure $\mathrm{S}_{7}$ ). In contrast to what was observed for the related network 2 , the polymers were all found to display porosity. The best results were obtained for the combination of $\mathbf{1}$ with $1,3-\mathrm{di}(1 \mathrm{H}-$ imidazol-1-yl)benzene. This material showed an apparent BET surface area of $314 \mathrm{~m}^{2} \mathrm{~g}^{-1}$, and an uptake of $\mathrm{H}_{2}$ and $\mathrm{CO}_{2}$ of $42 \mathrm{~cm}^{3} \mathrm{~g}^{-1}$ and $24 \mathrm{~cm}^{3} \mathrm{~g}^{-1}$, respectively (Figure S8). To our surprise, analysis of this network by powder XRD revealed an almost completely amorphous material. Furthermore, when crystallinity was enhanced by cooling a solution of the same building blocks in a controlled fashion $\left(-1{ }^{\circ} \mathrm{C} \mathrm{h}^{-1}\right)$, a powder with a much lower BET surface area of $27 \mathrm{~m}^{2} \mathrm{~g}^{-1}$ was obtained.49 This result suggests that whilst the tight packing of networks in the crystalline phase hinders the uptake of guest molecules, random ordering and inefficient packing in the amorphous phase can create channels for the uptake of guest molecules. These channels may even be transient, and subject to thermal fluctuations if the network is sufficiently flexible. The absences of well-defined pore sizes derived by DFT calculations support this hypothesis (Figure S9). Increasing either the length or the chelating angle of the diimidazole ligands in comparison to $1,3-\mathrm{di}\left({ }_{1} H-\right.$ imidazol-1-yl)benzene resulted in a decrease in measured surface area in the resulting network.

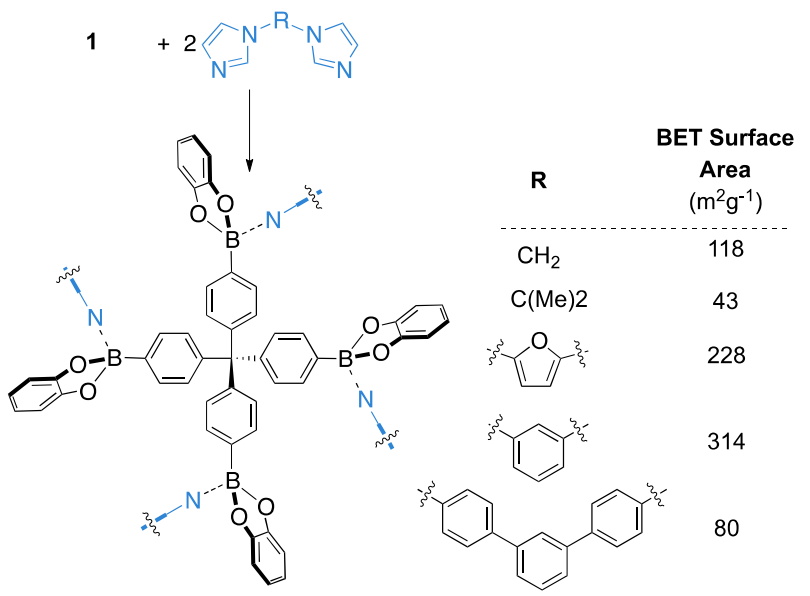

Scheme 4. Formation of $B \leftarrow$ Nnetworks with porosity.

The thermal lability of $\mathrm{B} \leftarrow$ bbonds allows the porous networks to be fully dissolved and reformed from so- 
lution by heating-cooling cycles, making these networks solution processable. Aside from distinguishing $\mathrm{B} \leftarrow \mathrm{N}$ networks from MOFs and COFs which are typically insoluble post-synthesis), this dissolution also presents an opportunity to repair any structural damage done to the network. To demonstrate these concepts, a B $\leftarrow$ Nhetwork consisting of 1 and $1,3-\mathrm{di}(\mathrm{r} H$ imidazol-1-yl)benzene was deliberately degraded by storage in a warm, high humidity environment (see SI for details). ${ }^{50}$ After 8 days, a significant loss of the surface area was observed ( $-35 \%)$. This loss can be correlated to the hydrolysis of the boronate esters, disrupting the $\mathrm{B} \leftarrow$ Nbonds. The network was then regenerated by thermally reversible dissolution through heating and cooling in a toluene/THF mixture (9:1). It was found that the reformed solid had recovered almost all of the original surface area (Figure S1o). A related example of surface assembled COF regeneration has previously been reported, ${ }^{5}$ although regeneration occurs without solution processing in this case.

In summary, we have explored the construction of $3 \mathrm{D}$ networks based on dative $\mathrm{B} \leftarrow$ Nbonds by combining polytopic $\mathrm{N}$-donor ligands with polyboronate esters. Building blocks with tetrahedral geometries were employed because they were expected to favor the formation of diamond-like structures. For polymer 6, this type of network topology was indeed observed. The crystalline networks 2 and 5 , on the other hand, display $2 \mathrm{D}$ and $\mathrm{1D}$ structures respectively. It is apparent that the intrinsic conformational flexibility around the $\mathrm{B} \leftarrow$ Nbond sites makes it difficult to exert control over the structure of $\mathrm{B} \leftarrow \mathrm{N}$ networks, even when using rigid ligands. Furthermore, the conformational flexibility favors tight-packing and interpenetration, reducing the void space in the crystalline state. The emergence of porosity was instead observed in amorphous B-N networks based on the tetraboronate ester $\mathbf{1}$ and ditopic imidazolyl ligands. These materials represent the first examples of $\mathrm{B} \leftarrow \mathrm{N}$ polymers with porosity. The straight-forward and scalable synthesis of amorphous $\mathrm{B} \leftarrow$ Nnetworks gives them a clear advantage over their crystalline counterparts. Another noteworthy feature of these materials is the possibility to repair hydrolytic damage by simple heating-cooling cycles.

\section{SUPPORTING INFORMATION}

Experimental details and analytical data.

\section{ACKNOWLEDGMENT}

The work was supported by the Swiss National Science Foundation and by the Ecole Polytechnique Fédérale de Lausanne (EPFL). We are grateful to Dr. Pascal
Schouwink (EPFL) for conducting the powder X-ray diffraction experiments.

\section{REFERENCES}

1. Zhou, H.-C.; Long, J. R.; Yaghi, O. M. Metal-Organic Frameworks (special issue). Chem. Rev. 2012, 12, 673-1268.

2. Lee, J.; Farha, O. K.; Roberts, J.; Scheidt, K. A.; Nguyen, S. T.; Hupp, J. T. Metal-organic framework materials as catalysts. Chem. Soc. Rev. 2009, 38, 1450-1459.

3. Kitagawa, S.; Kitaura, R.; Noro, S. I. Functional Porous Coordination Polymers. Angew. Chem., Int. Ed. 2004, 43, 2334-2375.

4. Waller, P. J.; Gándara, F.; Yaghi, O. M. Chemistry of Covalent Organic Frameworks. Acc. Chem. Res. 2015, 48, 30533063.

5. Ding, S. Y.; Wang, W. Covalent organic frameworks (COFs): From design to applications. Chem. Soc. Rev. 2013, $42,548-568$.

6. Feng, X.; Ding, X.; Jiang, D. Covalent organic frameworks. Chem. Soc. Rev. 2012, 41, 6010-6022.

7. Slater, A. G.; Cooper, A. I. Function-led design of new porous materials. Science 2015, 348, 988-998.

8. Wang, L. C.; Zheng, Q. Y. Hydrogen Bonding in Supramolecular Crystal Engineering. Hydrogen Bonded Supramolecular Structures; Lecture Notes in Chemistry; Springer: Berlin, Heidelberg, 2015; vol 87, pp 69-113.

9. Subramanian, S.; Zaworotko, M. J. Exploitation of the Hydrogen-Bond - Recent Developments in the Context of Crystal Engineering. Coord. Chem. Rev. 1994, 137, 357-401.

10. Aakeroy, C. B.; Seddon, K. R. The hydrogen bond and crystal engineering. Chem. Soc. Rev. 1993, 22, 397-407.

11. Li, B.; Zang, S. Q.; Wang, L. Y.; Mak, T. C. W. Halogen bonding: A powerful, emerging tool for constructing highdimensional metal-containing supramolecular networks. Coord. Chem. Rev. 2016, 308, 1-21.

12. Berger, G.; Soubhye, J.; Meyer, F. Halogen bonding in polymer science: From crystal engineering to functional supramolecular polymers and materials. Polym. Chem. 2015, 6, 3559-3580.

13. Yao, Z. F.; Wang, J. Y.; Pei, J. Control of $\pi-\pi$ Stacking via Crystal Engineering in Organic Conjugated Small Molecule Crystals. Cryst. Growth Des. 2018, 18, 7-15.

14. Claessens, C. G.; Stoddart, J. F. $\pi-\pi$ Interactions in Self-assembly. J. Phys. Org. Chem. 1997, 10, 254-272.

15. Yan, W.; Yu, X.; Yan, T.; Wu, D.; Ning, E.; Qi, Y.; Han, Y.; $\mathrm{Li}, \mathrm{Q}$. A triptycene-based porous hydrogen-bonded organic framework for guest incorporation with tailored fitting. Chem. Commun. 2017, 53, 3677-3680.

16. Adachi, T.; Ward, M. D. Versatile and Resilient HydrogenBonded Host Frameworks. Acc. Chem. Res. 2016, 49, 26692679 .

17. The concept of porosity requires a structure to retain its pores following the removal of solvents: Barbour, L. Crystal porosity and the burden of proof. Chem. Commun. 2006, 1163-1168.

18. Luo, J.; Wang, J.-W.; Zhang, J.-H.; Lai, S.; Zhong, D.-C. Hydrogen-bonded organic frameworks: design, structures and potential applications. CrystEngComm 2018, 20, 5884-5898.

19. E. Han, Y.-F.; Yuan, Y.-X.; Wang, H.-B. Porous HydrogenBonded Organic Frameworks. Molecules 2017, 22, 266300. 
20. Lü, J.; Cao, R. Porous Organic Molecular Frameworks with Extrinsic Porosity: A Platform for Carbon Storage and Separation. Angew. Chem., Int. Ed. 2016, 55, 9474-948o.

21. Patil, R. S.; Banerjee, D.; Zhang, C.; Thallapally, P. K.; Atwood, J. L. Selective $\mathrm{CO}_{2}$ Adsorption in a Supramolecular Organic Framework. Angew. Chem. Int. Ed., 2016, 55, 4523-4526.

22. Bury, W.; Walczak, A.; Leszczński, M. K.; Navaroo, J. A. R. Rational Design of Noncovalent Diamondoid $\mathrm{Mi}-$ croporous Materials for Low-Energy Separation of $\mathrm{C}_{6}-\mathrm{Hy}-$ drocarbons. J. Am. Chem. Soc. 2018, 140, 15031-15037.

23. Nikolayenko, V.; Castell, D.; van Heerden, D.; Barbour, L. Guest-Induced Structural Transformations in a Porous Halogen-Bonded Framework. Angew. Chem., Int. Ed. 2018, 57, 12086-12091.

24. Sokołowski, K.; Bury, W.; Justyniak, I.; Fairen-Jimenez, D.; Sołtys, K.; Prochowicz, D.; Yang, S.; Schröder, M.; Lewiński, J. Permanent Porosity Derived From the Self-Assembly of Highly Luminescent Molecular Zinc Carbonate Nanoclusters. Angew. Chem. Int. Ed. 2013, 52, 13414-13418.

25. Bezza, C. G.; Helliwell, M.; Warren, J. E.; Allan, D. R.; McKeown, N. B. Heme-Like Coordination Chemistry Within Nanoporous Molecular Crystals. Science, 2010, 327, 1627-1630.

26. Lewiński, J.; Kaczorowski, T.; Prochowicz, D.; Lipińska, T.; Justyniak, I.; Kaszkur, Z.; Lipkowski, J. Cinchona AlkaloidMetal Complexes: Noncovalent Porous Materials with Unique Gas Separation Properties. Angew. Chem. Int. Ed. 2010, 49, 7035-7039.

27. Kubo, Y.; Nishiyabu, R.; James, T. D. Hierarchical supramolecules and organization using boronic acid building blocks. Chem. Commun. 2015, 51, 2005-2020.

28. Dhara, A.; Beuerle, F. Reversible Assembly of a Supramolecular Cage Linked by Boron-Nitrogen Dative Bonds. Chem. Eur. J. 2015, 21, 17391-17396.

29. Salazar-Mendoza, D.; Cruz-Huerta, J.; Höpfl, H.; Hernández-Ahuactzi, I. F.; Sanchez, M. Macrocycles and coordination polymers derived from self-complementary tectons based on N -containing boronic acids. Cryst. Growth Des. 2013, 13, 2441-2454.

30. Sheepwash, E.; Zhou, K.; Scopelliti, R.; Severin, K. Self-assembly of arylboronate esters with pyridyl side chains. Eur. J. Inorg. Chem. 2013, 2558-2563.

31. Icli, B.; Sheepwash, E.; Riis-Johannessen, T.; Schenk, K.; Filinchuk, Y.; Scopelliti, R.; Severin, K. Dative boron-nitrogen bonds in structural supramolecular chemistry: multicomponent assembly of prismatic organic cages. Chem. Sci. 2011, 2, 1719-1721.

32. Christinat, N.; Scopelliti, R.; Severin, K. Boron-based rotaxanes by multicomponent self-assembly. Chem. Commun. 2008, 3660-3662.

33. Christinat, N.; Scopelliti, R.; Severin, K. Multicomponent assembly of boron-based dendritic nanostructures. J. Org. Chem. 2007, 72, 2192-2220.

34. Christinat, N.; Scopelliti, R.; Severin, K. A new method for the synthesis of boronate macrocycles. Chem. Commun. 2004, 85, 1158-1159.

35. Höpfl, H. The tetrahedral character of the boron atom newly defined-a useful tool to evaluate the $\mathrm{N} \rightarrow \mathrm{B}$ bond $J$. Organomet. Chem. 1999, 581, 129-149.

36. Sheepwash, E.; Krampl, V.; Scopelliti, R.; Sereda, O.; Neels, A.; Severin, K. Molecular Networks Based on Dative Boron-Nitrogen Bonds. Angew. Chem. Int. Ed. 2011, 50, 30343037.

37. Icli, B.; Solari, E.; Kilbas, B.; Scopelliti, R.; Severin, K. Multicomponent Assembly of Macrocycles and Polymers by
Coordination of Pyridyl Ligands to 1,4-Bis(benzodioxaborole)benzene. Chem. Eur. J. 2012, 18, 14867-14874.

38. Sheepwash, E.; Lusier, N.; Krause, M. R.; Noé, S.; Kubik, S.; Severin, K. Supramolecular polymers based on dative boron-nitrogen bonds. Chem. Commun. 2012, 48, 7808-7810.

39. Farfán, N.; Contreras, R. Carbon-13 nuclear magnetic resonance spectroscopy as a method to determine relative acidity of boron Lewis acids in pyridine complexes. $J$. Chem. Soc. Perkin Trans. 2 1987, 771-773.

40. Wieber, M; Künzel, W. Additionen von Stickstoffbasen an cyclische Organoborsaureester. Z. Anorg. Allg. Chem. 1974, 403, 107-115.

41. Weidman, H.; Zimmerman, H. K. Borsaure-Ester Von NSubstituierten Aminoalkoholen. Justus Liebigs Ann. Chem. 1958, 619, 28-35.

42. Cruz-Huerta, J.; Salazar-Mendoza, D.; HernándezParedes, J.; Hernández Ahuactzi, I. F.; Höpfl, H. N-containing boronic esters as self-complementary building blocks for the assembly of $2 \mathrm{D}$ and ${ }_{3} \mathrm{D}$ molecular networks. Chem. Commun. 2012, 48, 4241-4243.

43. Luisier, N.; Bally, K.; Scopelliti, R.; Fadaei, F. T.; Schenk, K.; Pattison, P.; Solari, E.; Severin, K. Crystal Engineering of Polymeric Structures with Dative Boron-Nitrogen Bonds: Design Criteria and Limitations. Cryst. Growth Des. 2016, 16, 660o-6604.

44. Luisier, N.; Scopelliti, R.; Severin, K. Supramolecular gels based on boronate esters and imidazolyl donors. Soft Matter 2016, 12, 588-593.

45. Eddaoudi, M.; Sava, D. F.; Eubank, J. F.; Adila, K.; Guillerm, V. Zeolite-like metal-organic frameworks (ZMOFs): design, synthesis, and properties. Chem. Soc. Rev., 2015, 44, 228-249.

46. Lu, W.; Yuan, D; Zhao, D.; Schilling, C. I.; Plietzsch, O.; Muller, T.; Bräse, S.; Guenther, J.; Blumel, J.; Krishna, R.; Li, Z.; Zhou, H.-C. Porous Polymer Networks: Synthesis, Porosity, and Applications in Gas Storage/Separation. Chem. Mater., 2010, 22, 5964-5972.

47. Lü, J.; Perez-Krap, C.; Trousselet, F.; Yan, Y.; Alsmail, N. H.; Karadeniz, B.; Jacques, N. M.; Lewis, W.; Blake, A. J.; Coudert, F.-X.; Cao, R.; Schröder, M. Polycatenated 2D Hydrogen-Bonded Binary Supramolecular Organic Frameworks (SOFs) with Enhanced Gas Adsorption and Selectivity. Cryst. Growth Des. 2018, 18, 2555-2562.

48. In order to solubilize the networks components at room temperature, the solid material was added to a mixture of $\mathrm{d}^{6}$ DMSO and water. Under these conditions, the hydrolysis of boronate esters disrupts the $\mathrm{B} \leftarrow \mathrm{N}$ bonds, triggering network disassembly.

49. Mastalerz previously reported a similar amorphous phase enhancement of BET surface area for organic cage molecules in the solid state: Schneider, M. W.; Oppel, I. M.; Ott, H.; Lechner, L. G.; Hauswald, H. J. S.; Stoll, R.; Mastalerz, M. Periphery-substituted [4+6] salicylbisimine cage compounds with exceptionally high surface areas: Influence of the molecular structure on nitrogen sorption properties. Chem. Eur. J. 2012, 18, 836-847.

50. A control sample stored under atmospheric conditions showed no appreciable loss in surface area over the same time period.

51. Guan, C.-Z.; Wang, D.; Wan, L.-J. Construction and repair of highly ordered 2D covalent networks by chemical equilibrium regulation. Chem. Commun., 2012, 48, 2943-2945. 
TOC graphic:

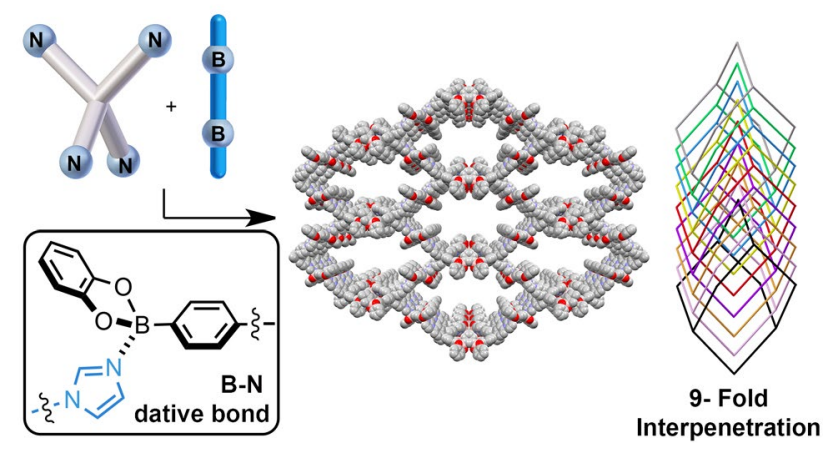

